\title{
Panorama da Literatura nas Ciências Naturais e na Biologia Acerca de Experiências Formativas Para a Inclusão de Estudantes com Deficiência Visual no
} Brasil

\author{
Danyele dos Santos da Silva*; David Santana Lopes**
}

\section{Resumo}

O diálogo entre o ensino e o processo de inclusão é ainda um desafio para educadores e o corpo estudantil. Dentre os estudantes com necessidades educativas especiais, aqueles com deficiência visual ocupam a segunda posição entre as maiores frequências de matriculados nas Instituições de Ensino Superior no Brasil. Entretanto, muitos professores possuem dificuldades em desenvolver suas práticas de ensino voltadas para atender tal grupo estudantil. Nas áreas das Ciências Naturais e da Biologia, inclusive nos cursos de licenciatura, a reconhecida abstração presente em seus conteúdos requer a adoção de métodos de ensino que explorem essencialmente habilidades iconográficas, dificultando o entendimento por parte dos estudantes com deficiência visual. A partir destas problemáticas, o presente estudo tem como objetivo identificar na literatura, nas áreas das Ciências Naturais e da Biologia, experiências formativas voltadas para a inclusão de estudantes com deficiência visual em interface com o ambiente universitário, além de propor um modelo de design pedagógico adaptado para o ensino desses estudantes. Três bases de dados foram consultadas durante o levantamento de 8 trabalhos (6 Artigos, 1 Dissertação e 1 Tese), ressaltando a escassez de trabalhos vinculados a experiências formativas para estudantes com deficiência visual quando relacionados à formação inicial, continuada e na atuação no Ensino Superior. Desta forma, com base nos resultados identificados é possível apontar a necessidade de mais investimentos no desenvolvimento de modelos pedagógicos e experiências formativas adaptadas para os estudantes com deficiência visual, potencializando as-

\footnotetext{
* Licenciada em Ciências Biológicas pela Universidade Federal da Bahia (UFBA). Brasil. E-mail: dany_pq07@ hotmail.com

** Mestre em Educação pela Universidade Federal da Bahia (UFBA). Brasil. E-mail: acdc.santana@gmail.com
}

Recebido em: 17/02/2020 - Aceito em: 20/07/2020.

$10.5335 /$ rbecm.v3i2.10632

http://creativecommons.org/licenses/by-nc-nd/4.0 
sim a atuação docente nas áreas das Ciências Naturais e Biológicas. Em complemento, a adoção de artefatos pedagógicos, como os jogos de tabuleiro, pode agregar a ludicidade à prática docente, além de oferecer possibilidades de adaptação no ensino de estudantes com deficiência visual.

Palavras-chave: Estudantes com Deficiência Visual; Educação Inclusiva; Ensino Superior; Ensino de Ciências; Ensino de Biologia.

\section{Perspectivas Iniciais}

O processo de inclusão de pessoas com necessidades educativas especiais advém de um movimento histórico demarcado/definido por extensos momentos de exclusão e práticas discriminatórias (VAZ et al., 2012). A elaboração de documentos e leis configuraram uma importante conquista na luta pela educação inclusiva, porém, além das políticas públicas existentes, que visam a garantia do acesso e permanência de estudantes no ambiente educacional, a formação de professores também é um ponto chave para a inclusão dos estudantes, tanto no âmbito da Educação Básica quanto no Ensino Superior (REIS; EUFRÁSIO; BAZON, 2010; PEDROSO; CAMPOS; DUARTE, 2013).

A capacitação de professores, sejam eles atuantes ou em formação inicial, é de suma importância para que os educadores saibam aceitar e respeitar as diferenças de seus estudantes (OLIVEIRA et al., 2011). Essa formação também reflete na capacitação em outras áreas, como na utilização de tecnologias assistivas (ZHOU et al 2011), que despontam como ferramentas de grande importância para o acesso de informações por estudantes surdos, com deficiência visual ${ }^{1}$ e dentre outras subjetividades (KELLY; SMITH, 2011).

Embora existam políticas pautadas na educação inclusiva, o processo formativo, por vezes, ainda é baseado em um perfil estudantil estereotipado, corriqueiro ao sistema de ensino brasileiro (GONÇALVES et al., 2013). Essa situação é um reflexo da formação por vezes insuficiente de professores na área da Educação Inclusiva (GONÇALVES et al., 2013), e embora o acesso ao Ensino Superior ocorra de forma desproporcional entre alunos com e sem deficiência visual (AMOROSO, 2019), os estudantes com tais subjetividades estão menos propensos a terminar a graduação

1 A expressão deficiência visual configura-se em meio a uma abordagem patológica, contudo ela será adotada em trechos neste estudo por se tratar de uma expressão ainda corriqueira aos documentos orientadores e nas literaturas externas ou não ao Brasil. 
(REED; CURTIS, 2011), demonstração que o processo de permanência também necessita estar em interface com a própria inclusão.

No Brasil, dentre os estudantes público-alvo da educação especial, os estudantes com deficiência visual estão na segunda posição entre as maiores frequências de matriculados nas Instituições de Ensino Superior. Em 2017, a soma das matrículas de estudantes com baixa visão ou cegos representou aproximadamente $32 \%$ das matriculas em cursos de graduação de alunos considerados público-alvo da educação especial (AMOROSO, 2019). Porém, no ambiente acadêmico, muitos professores detêm grandes dificuldades em desenvolver suas práticas de ensino em espaços que possuam estudantes com visão reduzida. Desta forma, tais docentes se deparam com obstáculos em realizar as adaptações didáticas necessárias para atender alunos com essas características (GONÇALVES et al., 2013).

Dentre os recursos adotados para a inclusão de alunos com deficiência visual, o uso de artefatos pedagógicos, como modelos didáticos, adaptados não somente contribuem para a inclusão de estudantes com deficiência visual a partir da percepção tátil, como também beneficiam o entendimento de alunos videntes. Sendo assim, essa prática pode contribuir na esfera formativa na contextualização do conteúdo, tornando-o acessível para todos (STELLA; MASSABNI, 2019).

No que se refere às áreas das Ciências Naturais e da Biologia, a reconhecida abstração presente em seus conteúdos mais básicos (DURÉ; ANDRADE; ABÍLIO, 2018) requerem em diversas situações a adoção de métodos de ensino que explorem essencialmente habilidades visuais. Desta forma, a abstração desses assuntos é acompanhada de gráficos, desenhos e fotografias, dificultando o entendimento por parte dos alunos com deficiência visual.

Em complemento, Oliveira (2018, p. 5) afirma que o uso de recursos didáticos adaptados "no processo de inclusão escolar no ensino de Ciências e Biologia [são] motivadores e facilitadores no processo de ensino [...] e o quanto ainda é necessário de pesquisas para diversas subáreas" que compõem tanto as Ciências Naturais como a Biologia. Desta forma, cada temática presente nessas áreas demanda a implementação de instrumentos adaptativos diferenciados a partir de abordagens lúdicas e também distintas. Nesse sentido, a formação dos professores desses campos do saber necessita lidar com o conjunto de especificidades inatas às mesmas, além de atribuir significado perante as subjetividades do seu público, no caso deste estudo os estudantes com deficiência visual. 
Portanto, com base nos pressupostos apresentados, esta produção acadêmica tem como intuito identificar na literatura, nas áreas das Ciências Naturais e da Biologia, experiências formativas voltadas para o ensino de estudantes com deficiência visual em interface com o ambiente universitário. Espera-se que as interfaces existentes entre a prática docente, perante esse grupo de estudantes, e o próprio ambiente acadêmico, seja através da formação inicial, continuada ou através da própria atuação nas Instituições de Ensino Superior, possam ser ainda mais detalhadas, expondo os obstáculos e dificuldades presentes não só na Educação Básica, como também nas Universidades.

\section{Contexto Histórico}

Durante o período da Grécia Antiga, o abandono de crianças com deficiência era uma prática muito comum. Já em países Europeus, durante a Idade Média, pessoas com deficiência eram perseguidas e mortas por serem associadas a atos de feitiçaria (TULLIO, 2015).

Pode-se considerar que a partir do momento no qual as diferenças e o que era assinalado como fora do modelo normativo passou da esfera de domínio da Igreja para se tornar objeto de estudo da medicina, o atendimento (biologizante) ao público com necessidades educativas especiais se iniciou (TULLIO, 2015). A atuação de médicos no início do século XVI deu início à modalidade de ensino da Educação Especial, a partir da tentativa de educar esses indivíduos que vinham sendo excluídos do ambiente educacional (VAZ et al., 2012), baseado na segregação desses em instituições residenciais, na chamada fase de institucionalização (TULLIO, 2015).

Até o início do século XIX, o atendimento especializado às pessoas com deficiência apresentava uma essência mais assistencialista do que educacional. A partir do século XX, houve a integração de alunos com deficiência em escolas regulares mediante a criação de salas especiais. Porém, somente no final deste mesmo século, que as ideias de uma educação inclusiva, isto é, o atendimento de estudantes com necessidades educativas especiais em salas regulares, começou a ganhar força (VAZ et al., 2012).

Esse período intensificou a relevância da educação inclusiva, com a elaboração de diversos documentos orientadores para a inserção desses estudantes na escola regular. Destaca-se, dentre eles, a Declaração de Salamanca, elaborada em 1994, 
a partir da Conferência Mundial sobre Necessidades Educativas Especiais da UNESCO (OLIVEIRA et al., 2011). Desta forma, a escola passa a ter a responsabilidade de adequar-se aos seus estudantes e não o oposto, divergindo das práticas discriminatórias dentro do ambiente escolar (VAZ et al., 2012).

No Brasil, a década de 1990 foi marcada pela assinatura de documentos norteadores pelo estado brasileiro, que incitaram a inclusão de estudantes e promoveram a ideia de que todo aluno tem o direito de acompanhar a escola regular (KASSAR, 2014), além da promulgação de leis que passaram a destinar para a Educação Especial capítulos e trechos específicos de discussão, como foi o caso da Lei de Diretrizes e Bases da Educação Nacional - LDBEN de 1996 (GARCIA; MICHELS, 2011). Houve avanço na discussão da integração escolar, porém, a utilização de certos termos nesses documentos, abriu espaço para que o ensino não ocorresse na rede regular de ensino, permanecendo assim a segregação de estudantes com deficiência em espaços especializados (GARCIA; MICHELS, 2011).

Em 2005, além da inclusão do Programa de Implementação da Sala de Recursos Multifuncionais para a Educação Básica, na esfera do Ensino Superior, o Programa Incluir despontou com o objetivo de garantir o acesso de pessoas com deficiência nas Instituições Federais de Ensino. Tal meta é pleiteada a partir do fomento na criação e estabilização de núcleos de acessibilidades nessas instituições, que são responsáveis pela integração dos estudantes à vida acadêmica (BRASIL, 2013a). Porém, além das políticas públicas existentes, que visam a garantia do acesso e permanência de estudantes no ambiente educacional, a formação de professores também é um ponto chave para a inclusão dos estudantes, tanto no âmbito da Educação Básica quanto no Ensino Superior (REIS; EUFRÁSIO; BAZON, 2010; PEDROSO; CAMPOS; DUARTE, 2013).

\section{Ensino de Estudantes com Deficiência Visual}

O movimento mundial em prol da educação inclusiva é constituído pela defesa do direito de todos os estudantes de ocuparem o mesmo espaço, aprendendo de forma conjunta sem qualquer tipo de discriminação (BRASIL, 2008). Fundamentada na concepção dos Direitos Humanos, a Educação Inclusiva estabelece um paradigma educacional que conjuga a diferença e a igualdade como valores indissociáveis. Além 
disso, ela trabalha no ideal de equidade formal a partir da contextualização das circunstâncias históricas que resultam em exclusão dentro e fora do ambiente escolar.

Contudo, de acordo com Batalha (2009, p. 1066) é imprescindível o reconhecimento de situações que "evidenciam a necessidade de confrontar as práticas discriminatórias e criar alternativas para superá-las”. Desta forma, a educação inclusiva assume um espaço de grande importância no debate a respeito da sociedade contemporânea e da função da escola na progressão da lógica da exclusão. Para a construção de sistemas educacionais inclusivos, é preciso repensar as políticas implicadas na temática "a partir dos referenciais para a construção de sistemas educacionais inclusivos, a organização de escolas e classes especiais passa a ser repensada, implicando uma mudança estrutural e cultural" (BRASIL, 2008, p. 1) em diferentes espaços formativos.

Tradicionalmente, segundo o documento orientador da Política Nacional de Educação Especial na Perspectiva da Educação Inclusiva (BRASIL, 2008, p. 1-2) "[...] a educação especial se organizou tradicionalmente como atendimento educacional especializado [AEE] substitutivo ao ensino comum, evidenciando diferentes compreensões, terminologias e modalidades que levaram à criação de instituições especializadas". Essas práticas perduraram por um longo período, até que o movimento em prol da inclusão de estudantes nas escolas culminou na elaboração de políticas públicas e documentos diretivos.

No Brasil, o termo Público-Alvo da Educação Especial (PAEE), atualmente instituído pelo decreto 7.611/11 (BRASIL, 2011), define que os estudantes público-alvo da educação especial, dentre eles, estudantes com deficiência visual, têm direito de receber, no contraturno das suas aulas, AEE em ambientes adaptados. Tal medida, em tese, visa garantir não somente a matrícula dos estudantes nas escolas, como também o seu sucesso e permanência no ensino regular (TORRES; SANTOS, 2015).

Em 2008, a promulgação da Política Nacional de Educação Especial na perspectiva da Educação Inclusiva (PNEE-EI) consistiu na elaboração de um documento norteador para a implantação de diversas notas técnicas e decretos. O Decreto 7.611/11 define o AEE como um "conjunto de atividades, recursos pedagógicos" (BRASIL, 2011, p. 1) e de acessibilidade organizados institucionalmente, a serem oferecidos de forma complementar ou suplementar no domínio das Salas de Recursos Multifuncionais (SRM) ou em Centros de Atendimento Educacional Especializado (TORRES; SANTOS, 2015). 
Além das políticas descritas acima, existem também políticas específicas para o estudante com deficiência visual. Inicialmente a Portaria $n^{\circ}$ 319/99 (BRASIL, 1999) traz diretrizes para a admissão de uma política de normas e diretrizes para o ensino, além da definição de critérios voltados à adoção e difusão do próprio sistema braille. Em 2003 foi instituída a Política Nacional do Livro através da Lei 10.753/03 (BRASIL, 2003), que garante o direito à leitura para pessoas com deficiência visual em seu Art. 1ㅜ, inciso XII. Já em 2004, o Decreto 5.296/04 (BRASIL, 2004), em seu Art. 58º, afirma que o Poder Público adotará procedimentos para estimular a disponibilização através do meio magnético, na formatação de texto, as obras públicas do país.

Desta forma, a partir de 2004 passe-se a ter uma maior atenção à elaboração e implementação efetiva de materiais didático-pedagógicos adaptados aos estudantes com deficiência visual. Nesse sentido, atualmente o Decreto 7.611/11 (BRASIL, 2011), declara que o Ministério da Educação e Cultura (MEC) prestará apoio técnico e financeiro com a inclusão de laptops com sintetizadores de voz e livros didáticos e paradidáticos em braille. Portanto, de acordo com Torres e Santos (2015, p. 45), “o Decreto 8.470 / 10 (BRASIL, 2010), reforça o que foi definido no decreto supracitado, porém expandindo tal suporte para os professores de educação básica”, demonstrando que uma gama de políticas públicas no país vem sendo definidas, contudo ao acesso de estudantes com deficiência visual aos espaços formativos, principalmente às Universidade, possuem obstáculos muito mais intricados (MACHADO, et al., 2019).

\section{Dificuldades de Acesso de Estudantes ao Ensino Superior}

O caminho para o acesso de estudantes com deficiência visual ao Ensino Superior é longo. Apesar de necessário, é comum que as escolas não apresentem recursos disponíveis ou deem o suporte aos professores para a execução de suas aulas. Além disso, a realização de aulas puramente expositivas, a partir do uso de livros didáticos e suas imagens, do quadro para a esquematização dos conteúdos e de projetores, sem as devidas adaptações, podem contribuir para a exclusão destes estudantes (SILVA; LADIM; SOUZA, 2014).

Ademais, as fragilidades tanto na formação inicial como continuada de professores quanto às temáticas vinculadas à Educação Inclusiva são refletidas diretamente na capacitação dos mesmos para proporcionar uma educação adaptada perante as 
subjetividades de seus estudantes (SILVA; LADIM; SOUZA, 2014). Ao não utilizar e nem produzir recursos didáticos específicos para educandos com deficiência visual, a aprendizagem dos mesmos é comprometida, tornando-a, incompleta e pautada, em sua maioria, na memorização de conceitos.

Desta maneira, é de suma importância que os professores adquiram as competências necessárias para a utilização e produção eficaz de recursos adaptados, visando proporcionar aos estudantes com deficiência visual oportunidades equitativas de aprendizado perante aos estudantes videntes, a partir de práticas e abordagens inclusivas (SILVA; LADIM; SOUZA, 2014). Tanto a inclusão destes estudantes, quanto a formação de professores é garantida pela Lei Brasileira de Inclusão (BRASIL, 2015), como descrito no:

[...] Art. 28. Incumbe ao poder público assegurar, criar, desenvolver, implementar, incentivar, acompanhar e avaliar: [...] II - aprimoramento dos sistemas educacionais, visando a garantir condições de acesso, permanência, participação e aprendizagem; [...] X - adoção de práticas pedagógicas inclusivas pelos programas de formação inicial e continuada de professores e oferta de formação continuada para o atendimento educacional especializado (BRASIL, 2015, p. 19-20).

Mesmo com a defasagem de aprendizado e oportunidades oferecidas aos estudantes com deficiência visual (SILVA; LADIM; SOUZA, 2014), estes se fazem presentes no Ensino Superior. Desta forma, é dever do Poder Público e através de suas Autarquias Públicas, como as Instituições Federais, garantir através da oferta de recursos a acessibilidade e serviços para o acesso, a inclusão e a permanência de estudantes em todos os níveis formativos. Não somente as barreiras físicas, como a disposição espacial da instituição de ensino, devem ser repensadas para oferecer maior acessibilidade, contudo as barreiras atitudinais, voltadas ao engajamento sociocultural (SANTOS; MENDONÇA; OLIVEIRA, 2015) também implicam em um grande obstáculo para que a pessoa com deficiência usufrua de seus direitos.

Assim como na Educação Básica, as dificuldades teórico-práticas de professores em Instituições de Ensino Superior também se fazem presentes para atuarem com a inclusão de estudantes com deficiência, incluindo àqueles com deficiência visual. A formação desses educadores é essencial para a adoção de práticas adaptativas que respeitem às subjetividades desses estudantes (SANTOS; MENDONÇA; OLIVEIRA, 2015), em associação com um espaço que seja pensado para a acessibilidade e disponibilização de recursos inclusivos. 


\section{De que Forma Podemos Contribuir para o Ensino Desses Estudantes?}

O processo de ensino-aprendizagem desenrola-se por diversas formas. Desde a corporeidade e até as interfaces com as percepções sensoriais entre o sujeito (estudante) e objeto (saberes) fazem parte do processo de construção de conhecimento, assim como as interações entre os mesmos (CARDINALI; FERREIRA, 2010). Desta forma, a aprendizagem é desenvolvida continuamente a partir da relação do organismo em seu ambiente, recebendo influência da história de vida de cada indivíduo, como é o exemplo dos estudantes com deficiência visual que descobrem o mundo ao seu redor com as mãos, sendo o tato o sentido de percepção mais adotado.

Desde cedo, é necessário que as crianças com deficiência visual desenvolvam competências ligadas à qualidade tátil diante do reconhecimento de diferentes formas, estruturas e texturas. De acordo com Cardinali e Ferreira (2010), a aprendizagem gradual de contornos, formas, tamanhos, assim como o peso de objetos, contribui para o reconhecimento de estruturas e de detalhes característicos de objetos. Em complemento, os autores ressaltam que:

[...] Além da textura, é preciso que se tenha um conhecimento tátil dos objetos à sua volta, compreendendo sua forma, tamanho e o contorno dos objetos, além de oferecer-lhes jogos que ajudem a diferenciar, comparar e associar formas de dificuldades crescentes e de diferentes tamanhos. Com essas dinâmicas, gradativamente, o estudante cego terá condições de observar formas mais complexas (CARDINALI; FERREIRA, 2010, p. 5).

Nesse sentido, a diversificação de dinâmicas, especificamente para o público de estudantes com deficiência visual, é fundamental para o processo de ensino dos mesmos. Em suma, segundo Torres e Santos (2005), certos equipamentos e materiais necessários na elaboração das salas de recursos multifuncionais seriam essenciais para esse grupo estudantil, como na adoção do dominó tátil, kit de lupas manuais, calculadora sonora, alfabeto braille, guia de assinatura, kit de desenho geométrico, soroban, reglete de mesa, punção, máquina de braille, impressora braille e dentre outras ferramentas.

Ainda acerca desses instrumentos de ensino, Oliveira (2018, p. 49) ressalta "que o recurso didático não seja visto como uma simples montagem e um conjunto de resultados, mas como um trabalho que leve a reflexão, análise, que gera questionamentos viabilizando a construção do saber também no docente”. Desta forma, 
ratifica-se a necessidade de não apenas direcionar a análise para essas ferramentas pedagógicas e de restringi-las corriqueiramente à Educação Básica (OLIVEIRA, 2018), o ambiente universitário é um espaço formativo tanto de formação docente (e de contato com a Educação Inclusiva) como também de inclusão de estudantes com necessidades especiais, como é o caso dos estudantes com deficiência visual.

Portanto, a elaboração de práticas com recursos didáticos adaptados, que apresentem conformação tátil a partir da utilização de relevos, modelos tridimensionais e ferramentas inclusivas permitem uma aproximação do que é apresentado a um estudante vidente. Enquanto os alunos videntes possuem uma gama de recursos visuais disponíveis, estes mesmos recursos podem se estabelecer como uma barreira para o aprendizado de estudantes com deficiência visual se usados de forma banalizada, visto que os mesmos precisam de recursos que estimulem às suas potencialidades sensoriais específicas (CARDINALI; FERREIRA, 2010).

\section{Percurso Metodológico}

O estudo seguiu os princípios da pesquisa qualitativa e exploratória (BARBOSA, 2017), mantendo tanto os procedimentos como os instrumentos metodológicos de análise vinculados à descrição e compreensão do fenômeno identificado, valorizando não só a esfera acadêmica, como ramificações a nível sociocultural, político e econômico que possam se entrelaçar com os resultados obtidos. Em síntese, os procedimentos metodológicos empregados podem ser divididos em duas etapas, a primeira vinculada a uma Revisão Sistemática da Literatura (FLICK, 2009), enquanto que a segunda se refere ao aporte didático de Behar (2009) para a elaboração de um Design Pedagógico adaptado para às subjetividades de estudantes com deficiência visual.

Para a análise do corpus obtido foi realizada uma análise documental da literatura a partir da utilização de uma ficha categórica de análise de conteúdo proposta com base nos pressupostos de Bardin (2016). Em suma, os princípios adotados se organizam em três fases: (1) a Pré-análise, que pode ser considerada a fase de sistematização, no qual foi feita uma leitura flutuante e foram decididos quais artigos seriam analisados (vide os fatores de inclusão, exclusão e termos delimitadores), assim como a elaboração dos indicadores que orientaram a interpretação desses documentos; (2) a Exploração do Material, diante da codificação, classificação e categorização desses artigos e, por fim, (3) o Tratamento dos Resultados no qual foi 
desenvolvida a inferência e interpretação das informações produzidas através do estudo semiótico dos dados categorizados anteriormente, buscando assim a validação e extrapolação dos resultados em questão.

No que se refere especificamente sobre a revisão da literatura, o período temporal para o levantamento do corpus de análise foi estabelecido entre os anos de 2005 (período considerado como marco temporal por conta da criação do Projeto Incluir pelo Ministério da Educação) até 2019. Os artigos científicos vinculados às áreas da Biologia e das Ciências Naturais foram obtidos a partir de revisão da Plataforma de Periódicos da Capes e da Plataforma SciELO, além da Plataforma de Dissertações e Teses da Capes, graças à relevância dessas bases de dados para a pesquisa no país. Os descritores considerados nas buscas foram Deficiência Visual e Ensino Superior em três idiomas (português, espanhol e inglês) a partir dos seguintes Critérios de Inclusão (CI) e de Exclusão (CE): (CI) Foram considerados apenas estudos vinculados à Biologia e à Ciências Naturais; (CE) Não foram considerados trabalhos que não estivessem inseridos nas áreas da Biologia e das Ciências Naturais.

Em complemento, considerou-se como trabalhos vinculados ao Ensino Superior todo estudo no qual o objeto de estudo estivesse em torno de questões que envolvessem a formação docente inicial e/ou continuada, além de experiências formativas presentes na própria atuação de professores no ambiente universitário. Em síntese, com base nos critérios apresentados o corpus de estudo foi definido e os princípios supracitados foram seguidos para descrição e análise das informações produzidas.

Por fim, como mencionado, os pressupostos adaptados de Behar (2009) foram base para elaboração de um design pedagógico adaptado para os estudantes com deficiência visual seguindo o aporte teórico descrito nesta produção acadêmica. Desta forma, Behar (2009, p. 27) propõe "para seleção do conteúdo, por parte do [...] professor, é preciso também levar em conta o design deste tipo de material [adaptado], se une fatores técnicos, gráficos e pedagógicos, se é motivador (ou não) para o aluno, se é interativo, entre outros aspectos", ou seja, se causa algum nível de engajamento por parte de cada estudante.

Portanto, será sugerido como modelo de intervenção um design adaptativo para estudantes deficientes visuais presentes em distintos espaços formativos. Os aspectos técnicos (quanto à viabilidade teórico-prática da intervenção), gráficos (relacionados à iconografia e demais aspectos sensoriais dos materiais didáticos adotados) e pedagógicos (referente ao objetivo de educacional pretendido) serão es- 
tabelecidos buscando articular ações que valorizem um processo inclusivo pautado nas subjetividades estudantis.

\section{Resultados e Discussão}

\section{Sistematização e Análise a partir da Revisão da Literatura}

Foi realizado um levantamento de trabalhos presentes na literatura que apresentem experiências formativas, ou seja, relatos de experiência na implementação de propostas pedagógicas e metodológicas utilizadas para o Ensino de Ciências e de Biologia e que visem proporcionar um processo de ensino-aprendizagem adaptado às subjetividades de estudantes com necessidades educativas especiais, em especial para aqueles com deficiência visual em espaços de ensino com interface com o ambiente universitário. Este levantamento abrangeu duas plataformas de periódicos acadêmicos (Plataforma Periódicos da Capes e a Scielo), além da Plataforma de Dissertações e Teses da Capes. A busca foi limitada em publicações entre os anos de 2005 e 2019, em decorrência, como já mencionado, da implementação do Programa Incluir no ano de 2005.

Foi identificado um total de 8 trabalhos acadêmicos (Quadro 1) que se encaixam nos critérios estabelecidos durante a seleção por estarem relacionados com estudos vinculados à inclusão de estudantes com deficiência visual a partir de experiências formativas relacionadas ao espaço acadêmico, através de pesquisas voltadas à formação inicial, continuada ou quanto à própria atuação de professores universitários nos cursos de Licenciatura em Ciências Naturais e em Biologia. Esses 8 trabalhos são organizados em 6 Artigos Científicos (75\%), 1 Dissertação (12,5\%) e 1 Tese (12,5\%). 
Quadro 1 - Relação de trabalhos acadêmicos encontrados a partir dos descritores utilizados na busca e organizados em ordem por tipo de trabalho.

\begin{tabular}{|l|l|l|}
\hline CATEGORIA DE ANÁLISE & \multicolumn{1}{|c|}{ AUTOR (ANO) } & \multicolumn{1}{c|}{ TOTAL (POR TIPO) } \\
\hline $\begin{array}{l}\text { Formação de professores } \\
\text { Para a Educação Básica }\end{array}$ & $\begin{array}{l}\text { Trief; Lengel; Baecher (2013) } \\
\text { Oliveira (2016) } \\
\text { Voos (2018) }\end{array}$ & $\begin{array}{l}\text { 1 Artigo, 1 Dissertação e 1 } \\
\text { Tese }\end{array}$ \\
\hline $\begin{array}{l}\text { Treinamento de Professo- } \\
\text { res da Educação Básica }\end{array}$ & $\begin{array}{l}\text { Kirch et al. (2005) } \\
\text { Kirch et al. (2007) }\end{array}$ & 2 Artigos \\
\hline Atuação no Ensino Superior & $\begin{array}{l}\text { Reis; Eufrásio; Bazon (2010) } \\
\text { Oliveira; Nascimento; Bianconi (2017) } \\
\text { Sorrell et al. (2017) }\end{array}$ & 3 Artigos \\
\hline \multicolumn{2}{|c|}{ TOTAL DE TRABALHOS IDENTIFICADOS } & 8 trabalhos \\
\hline
\end{tabular}

Fonte: Elaborado pelos autores.

No Quadro 1 estão elencados os 8 trabalhos identificados durante o levantamento que compõem o corpus de análise da pesquisa. Observa-se também que de 2005 a 2009 não foram encontrados trabalhos brasileiros publicados em nenhuma das plataformas investigadas com base nos descritores adotados. A partir de 2010 foi identificado um crescimento nas publicações brasileiras, que somaram 6 trabalhos entre 2010 e 2018, apresentando em 2017 o ano de maior produção, com um total de 2 publicações. Mesmo que estes dados indiquem que recentemente o ensino de estudantes com deficiência visual venha recebendo uma maior atenção e cuidado por parte dos pesquisadores no país quanto ao desenvolvimento de pesquisas e de propostas de adaptações para as Ciências Naturais e Biologia, ainda é um quantitativo reduzido perante o fato, como já descrito, de que o maior contingente de estudantes com deficiência no Ensino Superior são estudantes com déficits visuais.

Quadro 2 - Número de trabalhos por ano, entre 2005 e 2019.

\begin{tabular}{|c|c|c|c|c|c|}
\hline ANO & QUANTIDADE & ANO & QUANTIDADE & ANO & QUANTIDADE \\
\hline 2005 & 1 & 2010 & 1 & 2015 & 0 \\
\hline 2006 & 0 & 2011 & 0 & 2016 & 1 \\
\hline 2007 & 1 & 2012 & 0 & 2017 & 2 \\
\hline 2008 & 0 & 2013 & 1 & 2018 & 1 \\
\hline 2009 & 0 & 2014 & 0 & 2019 & 0 \\
\hline
\end{tabular}

Fonte: Elaborado pelos autores. 
Em seguida, com base nos pressupostos de Bardin (2010), após a análise dos títulos e resumos, os trabalhos foram divididos em três categorias (Quadro 3), obedecendo assim à etapa da categorização. Em suma, foram definidas as seguintes temáticas e ambientes de associação dos trabalhos: a) Formação de professores para a Educação Básica, b) Treinamento de professores da Educação Básica e c) Atuação no Ensino Superior. Cada tema abrangeu propostas de materiais didáticos, métodos e abordagens teórico-práticas distintas vinculadas ao ensino de estudantes com deficiência visual. Em seguida, com base nos pressupostos de Bardin (2010), após a análise dos títulos e resumos, os trabalhos foram divididos em três categorias (Quadro 3), obedecendo assim à etapa da categorização. Em suma, foram definidas as seguintes temáticas e ambientes de associação dos trabalhos: a) Formação de professores para a Educação Básica, b) Treinamento de professores da Educação Básica e c) Atuação no Ensino Superior. Cada tema abrangeu propostas de materiais didáticos, métodos e abordagens teórico-práticas distintas vinculadas ao ensino de estudantes com deficiência visual.

Quadro 3 - Categorias criadas e as suas definições.

\begin{tabular}{|l|l|}
\hline \multicolumn{1}{|c|}{ CATEGORIA DE ANÁLISE } & \multicolumn{1}{c|}{ DEFINIÇÃO } \\
\hline $\begin{array}{l}\text { Formação de professores para a Educação } \\
\text { Básica }\end{array}$ & $\begin{array}{l}\text { Trabalhos relacionados à formação de profes- } \\
\text { sores de Ciências e de Biologia durante a sua } \\
\text { graduação. }\end{array}$ \\
\hline $\begin{array}{l}\text { Treinamento de professores da Educação Bá- } \\
\text { sica }\end{array}$ & $\begin{array}{l}\text { Trabalhos relacionados à formação continuada } \\
\text { de professores de Ciências e de Biologia. }\end{array}$ \\
\hline Atuação no Ensino Superior & $\begin{array}{l}\text { Trabalhos relacionados à elaboração de mate- } \\
\text { riais didáticos para o Ensino de Ciências e de } \\
\text { Biologia, voltados para estudantes/professores } \\
\text { universitários }\end{array}$ \\
\hline
\end{tabular}

Fonte: Elaborado pelos autores.

Foram encontrados três trabalhos na categoria de Formação de professores para a Educação Básica. Uma série de fatores são essenciais na formação de professores e a ausência dos mesmos pode influenciar na futura atuação dos estudantes de cursos de licenciatura. A insuficiência formativa pode levar à aulas de qualidade questionável, com visões simplistas da Educação Científica (CARVALHO; FELICIANO; LUCAS, 2018). Dentre as deficiências formativas apresentadas pelos autores, estão: 
[...] a falta de conhecimento sobre saberes docentes, sobre as gestões de conteúdo e de classe empreendidas pelo professor, sobre o domínio e a utilização de diferentes abordagens metodológicas de ensino, o emprego de diferentes modalidades didáticas nas aulas, o uso inadequado da experimentação no ensino, o desconhecimento de estratégias didáticas específicas e advindas da Didática das Ciências e de didáticas ainda mais especializadas, como a Didática da Biologia, além da ausência do enfoque evolutivo, bioético, histórico-filosófico, multicultural e ambiental (CARVALHO; FELICIANO; LUCAS, 2018, p. 156).

No artigo de Trief, Lengel e Baecher (2013), foi proposta a elaboração de uma galeria de vídeos que disponibilizasse aos licenciandos livre acesso a conteúdos relacionados ao ensino de estudantes com deficiência visual. Entre os temas considerados importantes neste trabalho, a criação de vídeos sobre o processo de aprendizagem de estudantes com deficiência visual no laboratório de Ciências foi considerada relevante demonstrando a importância que recursos audiovisuais adaptados possam representar para o processo de ensino de estudantes com deficiência visual.

Na dissertação de Oliveira (2016) foi analisada, na perspectiva da educação inclusiva, a formação inicial de licenciandos de Biologia da Universidade Estadual de Santa Cruz (UESC). A autora destaca a necessidade de refletir a formação dos professores, visto que foi possível observar a "resistência dos professores em participar dos cursos de formação continuada, já que a maioria desacredita que possa se concretizar a inclusão em um ambiente formativo. Essa postura demonstra o reflexo de uma formação inicial excludente e de crenças que não foram repensadas nas licenciaturas" (OLIVEIRA, 2016, p.14).

Já na tese apresentada por Voos (2018), foram analisados os limites e as potencialidades da formação de docentes da Educação Especial para a atuação no Ensino de Ciências para estudantes com deficiência visual, a partir de um processo formativo junto a educadores especiais e deficientes visuais. A autora trabalha sob a perspectiva da apropriação de conhecimentos específicos referentes ao ensino de Ciências da Natureza por profissionais da Educação Especial, evidenciando a necessidade desses atuarem em conjunto com professores nas escolas para o atendimento das demandas estudantis específicas, evitando a atuação paralela e segregada ao ensino comum. Em complemento, a autora acredita ainda que:

[...] o ensino de Ciências da Natureza para estudantes cegos e baixa visão, na qualidade de um conteúdo do desenvolvimento profissional de docentes da Educação Especial, possa contribuir para o enfrentamento de possíveis barreiras educacionais presentes no processo educativo aos referidos estudantes. Porém, faz-se necessário esclarecer que a área de ensino de Ciências da Natureza possui aspectos muito específicos os quais precisam ser mediados por profissionais 
formados e que aqui defendemos um trabalho coletivo que envolva a participação de ambos os profissionais (VOOS, 2018, p.32).

Na categoria do Treinamento de Professores da Educação Básica, evidencia-se a importância da formação continuada, que permite aos professores construírem novos conhecimentos e refletirem criticamente as suas práticas (ALMEIDA; SCHEUNEMANN; LOPES, 2019). Essa aproximação entre as universidades públicas e as escolas públicas da Educação Básica também gera benefícios, visto que um dos objetivos das universidades "deve ser intervir e modificar os espaços sociais, com base nas pesquisas e estudos teóricos desenvolvidos. [...] ações conjuntas entre escola e universidade têm gerado resultados benéficos para ambas, culminando com reflexões e revisão de práticas, tanto docentes, quanto formativas nas universidades" (ALMEIDA; SCHEUNEMANN; LOPES, 2019, p. 254).

Foram analisados dois artigos de Kirch et al. (2005) e Kirch et al. (2007), que abordaram a realização de um workshop denominado CLASS Project. Esse projeto tem como objetivo oferecer treinamento para professores, para a promoção do acesso igualitário ao campo e laboratório de Ciências. Dessa forma, o workshop aborda questões referentes à adaptação e modificação de equipamentos, além de protocolos utilizados em laboratório. Em complemento, o projeto também propõem atuações práticas com estudantes com deficiência e outras especificidades educativas que não estão contempladas pela definição do público-alvo da Educação Especial no Brasil, sendo um exemplo a prática com estudantes com Transtorno do Déficit de Atenção com Hiperatividade (TDAH).

No que se refere à última categoria Ensino Superior, constata-se a preocupação com a formação dos docentes universitários e a criatividade para a adaptação de materiais para o ensino de estudantes com deficiência visual. Para Sousa e Sousa (2020) analisaram as práticas docentes de professores de Ciências e Biologia quanto à inclusão de estudantes com deficiência visual em uma escola de aplicação de uma universidade. Como abordado pelos autores:

A prática docente constitui reflexo da formação docente. Dessa maneira, é necessário que a formação inicial seja fonte de estímulo à criatividade, à valorização da diversidade, possibilite um processo rico em construção de conhecimentos, permitindo o reconhecimento de diferentes contextos educacionais voltados às necessidades dos sujeitos, visto que essas atitudes repercutirão nas práticas docentes desse professor. O papel do educador no ensino inclusivo é o incentivo à busca de conhecimento, valorizando as peculiaridades e procurando meios para driblar possíveis dificuldades (SOUSA; SOUSA, 2020, p. 316). 
A escola em questão possui um Núcleo de Assistência às Pessoas com Necessidades Educacionais Especiais (NAPNEE), que auxilia com o processo de inclusão de estudantes através da orientação e elaboração de estratégias de ensino, além da adaptação de atividades. Apesar da segurança gerada pela presença do NAPNEE, os docentes, em decorrência de uma formação que pouco contemplou temáticas de diversidade e inclusão, ainda demonstram dificuldades em promover metodologias inclusivas, sendo assim, "é possivel perceber que a responsabilidade pelo processo de inclusão almejado pela instituição, ainda se encontra centralizada, e de certa forma, bastante dependente das ações do Núcleo" (SOUSA; SOUSA, 2020, p.321).

Desta forma, foram encontrados três artigos cada um com uma abordagem diferente sobre o tema. Reis, Eufrásio e Bazon (2010) analisaram a formação de professores universitários que atuavam em um curso de Licenciatura em Ciências Biológicas e a sua atuação para o atendimento de estudantes com deficiência visual no sistema universitário. A formação dos professores universitários está diretamente relacionada ao desempenho desses no processo de inclusão, visto que os estudantes com deficiência visual "necessitam de diversas adaptações para terem acesso à linguagem vigente na escola, tanto em relação à escrita quanto aos materiais didáticos utilizados pelos professores, requerendo, assim, que, na formação docente, contemplem-se conteúdos pertinentes à compreensão dessa deficiência” (REIS; EUFRÁSIO; BAZON, 2010, p. 118).

Já Oliveira, Nascimento e Bianconi (2017) abordaram adaptações realizadas em uma aula prática de Bioquímica para a inclusão de estudantes com deficiência visual durante o experimento. Os autores demonstraram como adaptaram protocolos laboratoriais para que estudantes com deficiência visual possam interagir com o experimento a partir da utilização do tato, além de criarem modelos gráficos táteis de baixo custo. Por fim, Sorrell et al. (2017), elaboraram uma exibição online de arte científica, ou seja, desenhos artísticos que possuem o intuito de dinamizar e ilustrar assuntos por vezes abstratos ou de difícil compreensão acessível a estudantes com deficiência visual. Os autores utilizaram um software para que imagens de microscopia, produzidas por pesquisadores da universidade na qual foi realizada a ação, fossem descritas enquanto os estudantes aprendiam sobre as próprias pesquisas científicas realizadas pela universidade.

Assim como apresentado por Pedroso, Campos e Duarte (2013), os trabalhos encontrados na categoria de Formação de Professores para a Educação Básica 
evidenciam as dificuldades por parte do corpo docente em lidar com as individualidades de estudantes com deficiência visual e, principalmente, como os licenciandos questionam seus percursos acadêmicos e a organização curricular de seus cursos de graduação quanto aos déficits ligados à formação teórico-prática no âmbito da Educação Inclusiva. Em uma outra abordagem, Trief, Lengel e Baecher (2013, p. 55, tradução nossa) apresentam um projeto para a formação de professores, que tem como objetivo "definir claramente e criar uma biblioteca de videoclipes composta por clipes de 8 a 10 minutos que demonstrem exemplos de práticas de ensino para trabalhar com alunos com deficiência visual (ou seja, cegos ou com baixa visão)".

Embora a proposta elaborada pelos autores busque garantir o acesso à informação para os futuros professores sobre a área da inclusão de estudantes com deficiência visual, as temáticas sugeridas são demasiadamente amplas e não contemplam de forma satisfatória as especificidades das Ciências Naturais e Biologia.

Nesse sentido, é estabelecido, através das Diretrizes Curriculares Nacionais para a Formação de Professores da Educação Básica (BRASIL, 2002), que os dispositivos curriculares das Instituições de Ensino Superior devem oferecer carga horária obrigatória e complementar suficiente para atender a diversidade nos diferentes ambientes formativos, contemplando, assim, os entendimentos sobre as especificidades, inclusive, de estudantes com necessidades educativas especiais (PEDROSO; CAMPOS; DUARTE, 2013). Dessa forma, de acordo com estes mesmos autores, apesar das atuais demandas apresentadas pela Escola Pública e demais espaços de ensino, os Cursos de Licenciatura, como de Ciências Naturais e de Biologia, não têm assegurado os saberes pedagógicos necessários para uma formação que atenda as particularidades de alunos com necessidades educacionais especiais.

Anteriormente, Glat e Pletsch (2004, p. 3) já afirmavam que a preparação dos futuros professores para atender a esse público é uma questão bastante preocupante já que o "currículo dos cursos de formação de professores não contempla a nova realidade [...] em consequência, os futuros docentes continuarão despreparados para atuar sob novo paradigma da escola aberta à diversidade, resultando em prejuízo social e acadêmico" aos participantes.

Apesar da importância da formação continuada de professores para a sua atuação na inclusão de estudantes ser amplamente discutida, constituindo como um dos pontos vitais para a prática inclusiva efetiva nas escolas (OLIVEIRA et al., 2011), não foram encontrados trabalhos brasileiros que abordassem a temática do 
treinamento de professores da Educação Básica ou do Ensino Superior, mesmo que esta esteja garantida pela Lei Brasileira de Inclusão (BRASIL, 2015). A existência de trabalhos que promovam um workshop de treinamento de professores (KIRCH et al., 2007) sugere que a formação inicial dos licenciandos de outros países também não conta com os saberes básicos necessários para a promoção da inclusão escolar. Além disso, um workshop que tem como pretensão abordar todas as questões ligadas à inclusão em apenas duas semanas seria o suficiente para a formação e a atuação destes professores perante às subjetividades de seus estudantes? A resposta para esse questionamento pode transparecer óbvia, contudo, é recorrente a superficialidade no qual a Educação Inclusiva é tratada em cursos de formação inicial/continuada de professores. Desta forma, a trajetória formativa destes profissionais acaba, por vezes, não favorecendo a capacitação, treinamento e profissionalização necessárias para lidar com experiências teórico-práticas específicas como é o caso de salas de aulas com estudantes com deficiência visual.

Por fim, foram encontrados apenas três artigos quanto às experiências formativas vinculadas à Atuação no Ensino Superior, não havendo trabalhos publicados no âmbito da pós-graduação ligadas às áreas das Ciências Naturais e da Biologia. As pessoas com deficiência estão cada vez mais ocupando novos espaços, dentre estes, as universidades. Porém, assim como apresentado por Reis, Eufrásio e Bazon (2010, p.111), os professores universitários não estão preparados para a inclusão de alunos com deficiência visual, "tanto devido a lacunas na formação docente quanto devido à postura adotada pelo professor em sala de aula”. Além disso, a escassez de pesquisas sobre o tema inclusão e o Ensino de Ciências/Biologia dentro das próprias Instituições de Ensino Superior (IES) evidencia o desacordo entre a formação docente orientada pelas Diretrizes Nacionais, àquela que ocorre nas IES e a necessária perante às singularidades estudantis presentes na Educação Básica.

Embora as pesquisas envolvendo as temáticas de adaptação didático-pedagógica dentro de Ciências Naturais e da Biologia sejam escassas, as outras disciplinas inseridas dentro da área das Ciências da Natureza (Química e Física) aparentemente apresentam um foco maior nas pesquisas dentro do tema de inclusão de estudantes com deficiência visual. Durante o levantamento dos dados, diversos títulos de trabalhos relacionados a adaptações de materiais para os conteúdos de Física e Química foram identificados em grande quantidade nos resultados. Dentre os trabalhos citados, Cole e Slavin (2013); Viveiros (2013); Jesus (2014); Schwahn (2015); Carvalho 
(2015); Santos (2016) e Nascimento (2018) trazem reflexões diretas a recursos e uma diversidade de artefatos culturais adaptados ao ensino de estudantes com deficiência visual. Esses dados evidenciam ainda certo desinteresse ou estranheza por parte da academia, nas áreas da Ciências Naturais e da Biologia, em se aprofundar em temáticas por vezes tachadas como vinculadas apenas ao campo da Pedagogia, ao invés de uma abordagem transversal como é o caso da Educação Inclusiva.

Apesar da existência de Leis e Diretrizes que prezam pela igualdade de oportunidades para todos os estudantes, a inclusão dentro da sala de aula regular é afetada em decorrência da falta de recursos, infraestrutura e, por vezes, das deficiências na formação inicial/continuada dos professores, tanto na Educação Básica quanto no Ensino Superior, para lidar com as demandas e especificidades dos estudantes com deficiência visual. Em adição, destaca-se a necessidade de novas pesquisas na área, não somente para a produção de novos modelos e adaptações didáticas, através de planos de aula ou intervenções pedagógicas que fiquem involucradas exclusivamente na área das Ciências Naturais e da Biologia, mas que também seus dados publicados perpetuassem através da divulgação científica facilitando a réplica e readaptação destes recursos em diferentes salas e ambientes de ensino.

\section{Apresentação do Design Pedagógico Proposto}

Em meio a grande quantidade de conteúdos encontrados nas áreas das Ciências Naturais e Biologia, existem poucos trabalhos publicados que abordam métodos adaptados para o ensino de estudantes com deficiência visual. Procurando construir uma proposta efetiva que colabore com a superação dos desafios encontrados pelos professores ao realizarem modificações pedagógicas que prezem pela construção de conhecimentos por parte dos estudantes, foi elaborada uma intervenção didática, dentro do âmbito das Ciências Naturais e Biologia, que possa ser aplicada e replicada em múltiplos espaços.

Assim como apontado por Behar (2009), a seleção do conteúdo foi realizada levando em consideração os materiais que serão adaptados e o seu custo, assim como os aspectos pedagógicos, gráficos e técnicos a serem aplicados no modelo. Além disso, a temática escolhida faz parte de um conteúdo que perpassa por todos os níveis de ensino, podendo ser adaptado para aulas do Ensino Fundamental, Ensino Médio e para o Ensino Superior. 
Esta intervenção pode contribuir no processo de ensino-aprendizagem tanto para os estudantes com deficiência visual, quanto para os alunos videntes, e, contribuir também, na autonomia dos próprios estudantes. Ademais, a partir do modelo de Design Pedagógico abaixo (Quadro 4), os professores podem usufruir desta proposta na elaboração de práticas que tornem as aulas passíveis de uma maior adaptação quanto às subjetividades estudantis diante dos diversos conteúdos abstratos presentes nas Ciências Naturais como na Biologia.

Quadro 4: Modelo de Intervenção. Corpo humano - visualização através do toque.

\begin{tabular}{|c|c|}
\hline Professor(a): & $\begin{array}{l}\text { Grupo Alvo: Esta intervenção pode ser utilizada tanto } \\
\text { na Educação Básica quanto no Ensino Superior }\end{array}$ \\
\hline Temática Central & Sistemas do Corpo Humano. \\
\hline Pergunta e Relevância da Temática & $\begin{array}{l}\text { Como ocorrem as interações e relações entre o nosso } \\
\text { corpo e o meio ambiente? } \\
\text { A Fisiologia Humana busca compreender o funciona- } \\
\text { mento do nosso corpo, assim como analisar os pro- } \\
\text { cessos que ocorrem nele. Estudar esses processos é } \\
\text { fundamental para o autoconhecimento dos estudantes, } \\
\text { além de promover abordagens relacionadas à saúde, } \\
\text { bem-estar e qualidade de vida. }\end{array}$ \\
\hline Duração da Intervenção & 150 minutos (três aulas de 50 minutos cada). \\
\hline Objetivo Geral da Intervenção & $\begin{array}{l}\text { Ao final da intervenção espera-se que os estudantes } \\
\text { possam compreender e relacionar o funcionamento } \\
\text { dos sistemas fisiológicos humanos e os seus proces- } \\
\text { sos. }\end{array}$ \\
\hline Conteúdos Utilizados & $\begin{array}{l}\text { Dependendo da etapa de ensino do docente, a esco- } \\
\text { Iha do conteúdo poderá ser realizada a partir dos do- } \\
\text { cumentos: Base Nacional Comum Curricular (BRASIL, } \\
\text { 2017); Orientações Curriculares Nacionais do Ensino } \\
\text { Médio (BRASIL, 2006); Parâmetros Curriculares Na- } \\
\text { cionais + (BRASIL, 2000) e Diretrizes Curriculares Na- } \\
\text { cionais para o Ensino Fundamental (BRASIL, 2013b). }\end{array}$ \\
\hline
\end{tabular}




\begin{tabular}{|c|c|}
\hline $\begin{array}{l}\text { Sugestões de Estratégias de Ensino a } \\
\text { Serem Utilizadas }\end{array}$ & $\begin{array}{l}\text { A intervenção está dividida em três grandes momen- } \\
\text { tos, cada um a ser realizado dentro de uma aula de } 50 \\
\text { minutos. } \\
1^{\circ} \text { Momento da Intervenção: os estudantes deverão } \\
\text { expor o seu conhecimento acerca das temáticas que } \\
\text { constituem a Fisiologia Humana (com complementa- } \\
\text { ção das ideias pelo/a professor/a, caso seja neces- } \\
\text { sário). Em seguida, os estudantes serão divididos em } \\
\text { grupos por sistemas do corpo humano, e construirão } \\
\text { modelos didáticos táteis, a partir de leituras sobre o } \\
\text { tema (conteúdo presente no livro didático, reportagens } \\
\text { impressas, internet, etc). } \\
2^{\circ} \text { Momento da Intervenção: cada grupo deverá apre- } \\
\text { sentar o modelo do seu sistema para a turma, de } \\
\text { forma que todos possam explorar e interagir com as } \\
\text { construçães. } \\
3^{\circ} \text { Momento da Intervenção: realização da versão } \\
\text { adaptada do jogo When I Dream } \odot \text {. }\end{array}$ \\
\hline Recursos Didáticos e Materiais & $\begin{array}{l}\text { Projetor Multimídia (ou Notebook para exibição do } \\
\text { vídeo) ou apostila explicativa ou reportagens impres- } \\
\text { sas sobre o tema a ser discutido; pilotos (marcadores } \\
\text { de quadro); isopor, massa de modelar, papel, cartolina, } \\
\text { tinta, canetas coloridas, papelão, entre outros mate- } \\
\text { riais passíveis de serem usados na construção dos } \\
\text { modelos didáticos; Lupa; Jogo (Versão adaptada do } \\
\text { jogo When I Dream® ). }\end{array}$ \\
\hline $\begin{array}{l}\text { Design Pedagógico voltado para estu- } \\
\text { dantes com deficiência visual } \\
\text { (BEHAR, 2009) }\end{array}$ & $\begin{array}{l}\text { a) Fatores Técnicos: a escrita deve ser feita com letras } \\
\text { maiúsculas e em negrito. Tanto as imagens quanto os } \\
\text { textos devem ter tamanho o suficiente para que possa } \\
\text { ser utilizado recursos de tecnologia assistiva (como } \\
\text { lupas). } \\
\text { b) Fatores Gráficos: os modelos didáticos devem ser } \\
\text { elaborados com diferentes texturas visando utilização } \\
\text { do tato; as cartas do jogo devem ser adaptadas em } \\
\text { alto relevo, com elementos que façam associação com } \\
\text { os temas relacionados à intervenção. } \\
\text { c) Fatores Pedagógicos: Teoria Sócio-interacionista de } \\
\text { Vygotsky. }\end{array}$ \\
\hline Referências & $\begin{array}{l}\text { As referências a serem adotadas, além das orienta- } \\
\text { ções nacionais para educação, deverão acompanhar } \\
\text { as especificidades área em questão. }\end{array}$ \\
\hline
\end{tabular}

Fonte: Elaborado pelos autores. 
Baseado no jogo When I Dream $\mathbb{C}^{2}$ que consiste na mecânica festiva/familiar, ocorre em um jogo de rodadas, no qual um(a) jogador(a) (estudante) assume o papel do Sonhador e não pode visualizar as cartas que serão trabalhadas na rodada, enquanto os outros jogadores (estudantes) recebem cartas que indicam se irão ajudar ou atrapalhar o sonhador. Ao longo da rodada, o sonhador deve adivinhar qual o elemento que está representado na carta, através das dicas dos outros alunos, que devem descrever o elemento usando uma palavra.

Figura 1: Imagens que representam o jogo When I Dream@ adotado no modelo de Design Pedagógico.
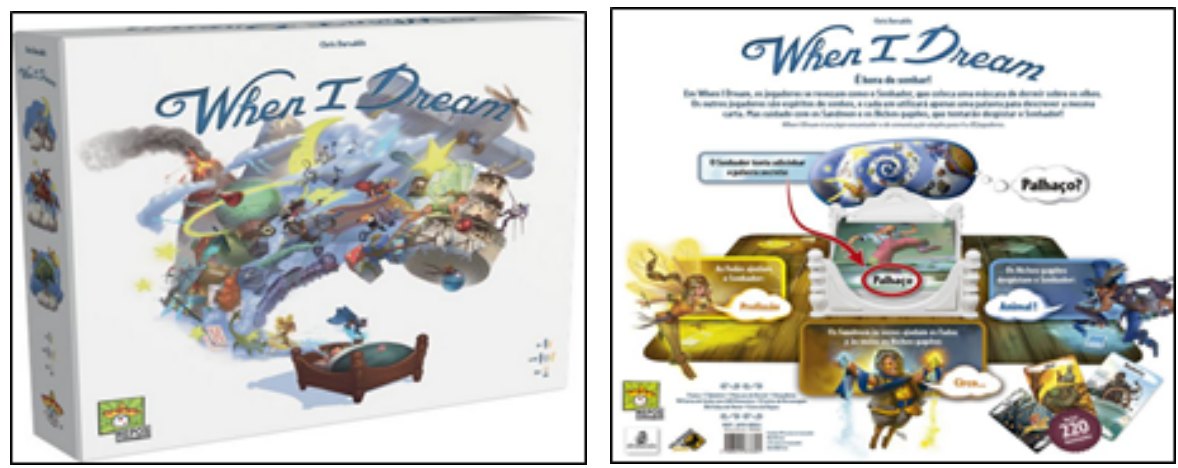

Fonte: Imagem à esquerda https://www.ludoteca.com.br e imagem à direita https://www.bodogami.com.br

As cartas são depositadas em duas pilhas: respostas certas ou erradas. Os pontos são distribuídos de acordo com a função de cada aluno (um ponto para cada carta certa no qual o sonhador e os alunos tinham como missão ajudar e um ponto para cada carta errada para quem tinha como missão atrapalhar o sonhador). No fim da rodada, o sonhador pode ganhar pontos extras se lembrar de todas as palavras que utilizou durante o turno.

A adaptação do jogo se dá a partir da criação de cartas com a temática escolhida pelo docente. As cartas, assim como as da versão original, devem ser iconográficas e com fontes grandes. É recomendado a utilização de contrastes entre os textos e imagens com o fundo da carta, as cores a serem utilizadas para o contraste vão variar de acordo com a especificidade de casa aluno. Em caso de adaptação para estudantes cegos é possível recriar as cartas com texturas nas imagens e a presença dos textos também em Braille.

2 Informações adaptadas do jogo When I Dream $@$, criado em 2016 pelo designer Chris Darsaklis e lançado no Brasil pela Editora Galápagos Jogos. (Fonte: https://www.ludopedia.com.br/jogo/when-i-dream) 
O jogo segue o pressuposto de que os estudantes têm conhecimento da palavra que deve ser adivinhada. Tanto o jogador da rodada quanto os demais participantes estão em constante reflexão do conteúdo apresentado em cada carta, desta forma, é possível trabalhar a atividade como prática de revisão ou até mesmo para uma melhor fixação do conteúdo proposto. No caso de uma prática utilizando conceitos de fisiologia humana, a carta deverá ter uma imagem e um texto referente a mesma (coração, por exemplo), e os estudantes deverão utilizar conceitos para ajudar ou enganar o jogador da rodada, até que o tempo se esgote e seja trabalhado o maior número possível de conceitos.

Em síntese, a partir do uso de cartas que estimulem o tato (com a presença de texturas e variações de fonte/cor) é possível desenvolver uma intervenção lúdica que ofereça para diferentes públicos diferentes sensações diante do processo de aprendizagem de uma temática (Corpo Humano) que perpassa todos os níveis de ensino, podendo então se adequar aos diferentes ambientes formativos, a depender da profundidade e especificidade no qual o assunto será abordado. Desta forma, a partir de jogos modernos já existentes e dentre outras ferramentas de ensino citadas ao longo deste estudo é possível apontar adaptações que ofereçam oportunidades de inclusão para estudantes com deficiência visual em meio a intervenções que estimulem o lúdico e os diferentes canais de aprendizagem dos mesmos.

\section{Considerações Finai}

O presente estudo apresentou como objetivo identificar na literatura, nas áreas das Ciências Naturais e da Biologia, experiências formativas voltadas para a inclusão de estudantes com deficiência visual em interface com o ambiente universitário. Apesar disso, uma parte considerável dos trabalhos encontrados estavam pautados na formação (ou na sua falta) de professores, sejam estes atuantes na Educação Básica ou no Ensino Superior. De acordo com os resultados obtidos, é evidente o crescimento de trabalhos produzidos na área, mas seriam estes o suficiente para certificar uma educação de qualidade a este público?

Em complemento foi proposto um modelo de design pedagógico adaptado ao ensino de estudantes com deficiência visual. Neste modelo foi possível elencar um conjunto de artefatos educacionais em associação direta com às demandas e subjetividades de estudantes com deficiência visual. A adoção de um jogo de tabu- 
leiro moderno é justificável por agregar à prática docente os princípios básicos da ludicidade, além de oferecer condições viáveis tanto pelo fácil acesso a esse artefato como também pelas possibilidades de adaptação, inclusive, como apontado, para estudantes cegos. Desta forma, os fatores técnicos, gráficos e pedagógicos, não apenas do jogo utilizado neste estudo, mas de outros potenciais exemplos disponíveis na atualidade podem contribuir para um processo de ensino de conteúdos abstratos e, por vezes, essencialmente visuais como é o caso dos assuntos adotados na esfera das Ciências da Natureza.

Espera-se que a partir da leitura deste trabalho, esteja evidente a carência de trabalhos pautados para o ensino de estudantes com deficiência visual no Ensino de Ciências e Biologia no âmbito na Educação Básica, mas especialmente que seja notório a escassez de trabalhos produzidos visando a educação de estudantes no Ensino Superior. Aproximadamente um terço das matrículas dos estudantes público-alvo da Educação Especial no Ensino Superior é composta por estudantes com deficiência visual. Esse resultado evidencia a necessidade de maiores investimentos em pesquisas dentro da área da inclusão de estudantes do Ensino Superior, demonstrando ainda, por vezes, o despreparo das Universidade e do corpo docente para a atuação inclusiva em sala de aula. Além disso, a capacitação na formação de novos profissionais, assim como a garantia de uma formação continuada para os professores que já estão atuando na área é de grande importância e não tem sido oferecida de forma satisfatória no Brasil.

Nesse sentido, é necessário que sejam tomadas medidas para que o que está previsto pelas diversas Leis e Decretos seja efetivamente cumprido. Este processo abarca desde a implementação de recursos nas escolas e universidades até a reestruturação das práticas pedagógicas realizadas pelos professores durante as suas aulas.

Conclui-se que há um extenso percurso para a inclusão de estudantes com deficiência visual no ensino regular. As pessoas com deficiência visual estão entre as maiores taxas das matrículas nas universidades e é responsabilidade destas instituições oferecer condições para o acesso e, principalmente, a permanência destes estudantes na graduação/pós-graduação, não limitando-se apenas à elaboração e disponibilização de recursos adaptados, como também no próprio engajamento de gestores, professores e estudantes quanto à importância no processo de inclusão efetiva de estudantes com deficiência visual no ambiente acadêmico. 


\section{Overview of Literature in Natural Sciences and Biology About Formative Experiences for the Inclusion of Students with Visual Disabilities in Brazil}

\section{ABSTRACT}

The dialogue between teaching and the inclusion process is still a challenge for educators and the student body. Among students with special educational needs, those with visual impairments occupy the second position among the highest enrollment frequencies in Higher Education Institutions in Brazil. However, many teachers have difficulties in developing their teaching practices aimed at serving this student group. In the areas of Natural Sciences and Biology, including undergraduate courses, the recognized abstraction present in its contents requires the adoption of teaching methods that essentially explore iconographic skills, making it difficult for students with visual impairments to understand. Based on these problems, the present study aims to identify in the literature, in the areas of Natural Sciences and Biology, formative experiences aimed at the inclusion of students with visual impairments in interface with the university environment, in addition to proposing a pedagogical design model adapted for the teaching of these students. Three databases were consulted during the survey of 8 papers (6 Articles, 1 Dissertation and 1 Thesis), highlighting the scarcity of papers linked to training experiences for students with visual impairments when related to initial, continuing education and acting in Higher Education. Thus, based on the results identified, it is possible to point out the need for more investments for the development of pedagogical models and training experiences adapted for students with visual impairments, thus enhancing the teaching performance in the areas of Natural and Biological Sciences. In addition, the adoption of pedagogical artifacts, such as board games, can add playfulness to teaching practice, in addition to offering possibilities for adaptation in the teaching of visually impaired students.

Keywords: Visually Impaired Students; Inclusive education; University education; Science teaching; Biology teaching.

\section{Referências}

ALMEIDA, Caroline Medeiros Martins de; SCHEUNEMANN, Camila Maria Bandeira; LOPES, Paulo Tadeu Campos. Formação continuada para professores em serviço do Ensino Fundamental Séries Iniciais: Aprendizagem Significativa e mapas conceituais. Revista Brasileira de Ensino de Ciências e Matemática, v. 2, n. 2, 2019.

AMOROSO, Sônia Regina Basili. INCLUSÃO DO DEFICIENTE NO ENSINO SUPERIOR: uma perspectiva para a inclusão social. Humanidades e Tecnologia (FINOM), v. 1, n. 15, p. 115$135,2019$.

BARBOSA, Jonei Cerqueira. Abordagens Teóricas e Metodológicas na Educação Matemática: Aproximações e Distanciamentos. In: REUNIÃO NACIONAL DA ANPED, 38. 2017, São Luís 
(Maranhão). Anais eletrônicos... São Luís: ANPEd, 2017. Disponível em: http://38reuniao. anped.org.br/sites/default/files/resources/programacao/trabalhoencom_38anped_2017_gt19_jonei_cerqueira_barbosa.pdf. Acesso em: 3 nov. 2019.

BARDIN, Laurence. Análise de conteúdo. Lisboa: Edições, 2016.

BATALHA, Denise Valduga. Um breve passeio pela política nacional de educação especial na perspectiva da educação inclusiva brasileira. In: CONGRESSO NACIONAL DE EDUCAÇÃO, 9. 2009, Curitiba. Anais eletrônicos... Curitiba: EDUCERE, 2009. Disponível em: https://educere. bruc.com.br/arquivo/pdf2009/1915_1032.pdf. Acesso em: 11 nov. 2019

BEHAR, Patrícia Alejandra. Modelos pedagógicos na educação a distância. Porto Alegre: Artmed, 2009.

BRASIL. Ministério da Educação. Lei n. ํㅜ 9.394, de 20/12/1996. Estabelece a lei de diretrizes e bases da educação nacional. Brasília, DF, 1996.

BRASIL. Ministério da Educação. Portaria 319, de 26 de fevereiro de 1999. Política de diretrizes e normas para o uso, o ensino, a produção e a difusão do Sistema Braille em todas as modalidades de aplicação. Brasília, DF, 1999.

BRASIL. Ministério da Educação. Parâmetros Curriculares Nacionais + para o Ensino Médio. Brasília, DF, 2000.

BRASIL. Ministério da Educação. Parecer №: CNE/CP 009/2001. Diretrizes Curriculares Nacionais para a Formação de Professores da Educação Básica, em nível superior, curso de licenciatura, de graduação plena. Brasília, DF, 2002.

BRASIL. Ministério da Educação. Lei 10.753 de 30 de outubro de 2003. Institui a Política Nacional do Livro. Brasília, DF, 2003.

BRASIL. Ministério da Educação. Decreto-lei no ${ }^{\circ}$ 5.296, de 2 de dezembro de 2004. Regulamenta as Leis nos 10.048, de 8 de novembro de 2000. Brasília, DF, 2004.

BRASIL. Ministério da Educação. Orientações Curriculares Nacionais. Brasília, DF, 2006.

BRASIL. Ministério da Educação. Política nacional de educação especial na perspectiva da educação inclusiva. Brasília, DF, 2008.

BRASIL. Secretaria de Educação Especial Manual de Orientação: Programa de Implantação de Sala de Recursos Multifuncionais. Brasília, DF, 2010.

BRASIL. Ministério da Educação. Decreto no 7.611 , de 17 de novembro de 2011. Dispõe sobre a educação especial, o atendimento educacional especializado e dá outras providências. Brasília, DF, 2011.

BRASIL. Ministério da Educação. Documento Orientador: Programa Incluir - Acessibilidade na Educação Superior. Brasília, DF, 2013a.

BRASIL. Ministério da Educação. Diretrizes Curriculares Nacionais para o Ensino Fundamental. Brasília, DF, 2013b.

BRASIL. Ministério da Educação. Lei nํㅜㄹ.146, de 6 de julho de 2015. Institui a Lei Brasileira de Inclusão da Pessoa com Deficiência (Estatuto da Pessoa com Deficiência). Brasília, DF, 2015. 
BRASIL. Ministério da Educação. Conselho Nacional de Educação. Resolução CNE/CP № 2, de 22 de dezembro de 2017, que institui a Base Nacional Comum Curricular. Brasília, DF, 2017.

CARDINALI, Sandra Mara Mourão; FERREIRA, Amauri Carlos. A aprendizagem da célula pelos estudantes cegos utilizando modelos tridimensionais: um desafio ético. Revista Benjamin Constant, v. 46, n. 46, p. 5-12, 2010.

CARVALHO, Caroline de Souza; FELICIANO, Fabiana Juliana; LUCAS, Lucken Bueno. Abordagens metodológicas de ensino na formação inicial de professores de Ciências e Biologia: um curso formativo sobre o enfoque histórico-filosófico da Ciência. Revista Brasileira de Ensino de Ciências e Matemática, v. 1, n. 2, p. 155-173, 2018.

CARVALHO, Julio Cesar Queiroz de. Ensino de física e deficiência visual: possibilidades do uso do computador no desenvolvimento da autonomia de alunos com deficiência visual no processo de inclusão escolar. São Paulo: USP, 2015. Tese, Universidade de São Paulo, 2015.

COLE, Ryan; SLAVIN, Alan. Use of a video assistive device in a university course in laboratory science: A case study. Journal of Visual Impairment \& Blindness, v. 107, n. 4, p. 311-315, 2013.

SOUSA, Louíze Roberta Mafra de; SOUSA, Carlos Erick Brito de. Práticas docentes no ensino de ciências e biologia para alunos com deficiência visual: uma análise à luz da perspectiva inclusiva. Revista Educação, Artes e Inclusão, v. 16, n. 3, p. 312-342, 2020.

DURÉ, Ravi Cajú; ANDRADE, Maria José Dias de; ABÍLIO, Francisco José Pegado. Ensino de Biologia e contextualização do conteúdo: quais temas o aluno de ensino médio relaciona com o seu cotidiano. Experiências em Ensino de Ciências, v.13, n. 1, p. 259-271, 2018.

FLICK, Uwe. Introdução à pesquisa qualitativa. Porto Alegre: Artmed, 2009.

GARCIA, Rosalba Maria Cardoso; MICHELS, Maria Helena. A política de educação especial no Brasil (1991-2011): uma análise da produção do GT15-educação especial da ANPED. Revista Brasileira de Educação Especial, v. 17, n. SPE1, p. 105-124, 2011.

GLAT, Rosana; PLETSCH, Márcia Denise. O papel da universidade frente às políticas públicas para educação inclusiva. Revista Benjamin Constant, v. 29, n. 1, p. 3-8, 2004.

GONÇALVES, Fábio Peres; REGIANI, Anelise Maria; AURAS, Samuel Rohling; SILVEIRA, Thiele Schwerz; COELHO, Juliana Cardoso; HOBMEIR, Ana Karina Timbola. A educação inclusiva na formação de professores e no ensino de química: a deficiência visual em debate. Química Nova na Escola, v. 35, n. 4, p. 264-271, 2013.

JESUS, Raine Luiz de. O Ensino de Química Através de Maquetes Didáticas de Estruturas Moleculares a Estudantes com Deficiência Visual de uma Escola Pública de Manaus. Manaus: UEA, 2014. Dissertação, Universidade do Estado do Amazonas, 2014.

KASSAR, Mônica de Carvalho Magalhães. A formação de professores para a educação inclusiva e os possíveis impactos na escolarização de alunos com deficiências. Cad. CEDES (Campinas) v. 34, n. 93 , p. 207-224, 2014.

KELLY, Stacy; SMITH, Derrick. The impact of assistive technology on the educational performance of students with visual impairments: A synthesis of the research. Journal of Visual Impairment \& Blindness, v. 105, n. 2, p. 73-83, 2011.

$\mathrm{KIRCH}$, Susan et al. Inclusive science education: Classroom teacher and science educator experiences in CLASS workshops. School Science and Mathematics, v. 105, n. 4, p. 175-196, 2005. 
$\mathrm{KIRCH}$, Susan et al. Reflections of educators in pursuit of inclusive science classrooms. Journal of Science Teacher Education, v. 18, n. 4, p. 663-692, 2007.

MACHADO, Maíra Souza et al. Panorama de publicações no ensino de ciências e educação inclusiva: o que tem sido produzido? Revista Brasileira de Ensino, Ciência e Tecnologia (Ponta Grossa), v. 12, n. 2, p. 395-426, 2019.

NASCIMENTO, Willdson Robson Silva do. Os efeitos da prática do goalball no processo da mobilização da aprendizagem de alguns fenômenos e conceitos físicos da mecânica para alunos com deficiência visual nas aulas de física. Bauru: Unesp, 2018. Tese, Universidade Estadual Paulista Júlio de Mesquita Filho, 2018.

OLIVEIRA, Felipe; NASCIMENTO, Agatha; BIANCONI, Maria. Teaching Enzyme Activity to the Visual Impaired and Blind Students. Technologies, v. 5, n. 3, p. 52, 2017.

OLIVEIRA, Mayara Lustosa et al. Educação inclusiva e a formação de professores de ciências: o papel das universidades federais na capacitação dos futuros educadores. Revista Ensaio, v. 13, n. 3, p. 99-117, 2011.

OLIVEIRA, Rafaela. Formação de professores de biologia na perspectiva da inclusão de alunos com deficiência. Ilhés: UESC. Tese, Universidade Estadual de Santa Cruz, 2016.

OLIVEIRA, Andressa. Um olhar sobre o ensino de ciências e biologia para alunos deficientes visuais. São Mateus: UFEP, 2018. Tese, Universidade Federal do Espírito Santo, 2018.

PEDROSO, Cristina Cinto Araujo; CAMPOS, Juliane Aparecida de Paula Perez; DUARTE, Márcia. Formação de professores e educação inclusiva: análise das matrizes curriculares dos cursos de licenciatura. Educação Unisinos, v. 17, n. 1, p. 40-47, 2013.

REED, Maureen; CURTIS, Kathryn. High school teachers' perspectives on supporting students with visual impairments toward higher education: Access, barriers, and success. Journal of Visual Impairment \& Blindness, v. 105, n. 9, p. 548-559, 2011.

REIS, Michele Xavier dos; EUFRÁSIO, Daniela Aparecida; BAZON, Fernanda Vilhena Mafra. A formação do professor para o ensino superior: prática docente com alunos com deficiência visual. Educação em Revista, v. 26, n.1, p. 111-130, 2010.

SANTOS, André Luis Tato Luciano dos. Atividades multissensoriais para o ensino de física. São Paulo: USP, 2016. Tese, Universidade de São Paulo, 2016.

SANTOS, Roseli Albino dos; MENDONÇA, Suelene Regina Donola; OLIVEIRA, Mércia Aparecida Cunha de. Universitários Cegos: a visão dos alunos e a (falta de visão) dos professores. Revista e-Curriculum, v. 13, n. 4, p. 888-907, 2015.

SCHWAHN, Maria Cristina Aguirre. Aprendizado de geometria molecular e representações atomísticas com o uso de modelos moleculares: análise das imagens mentais de estudantes com cegueira congênita. Rio Grande do Sul: Ulbra, 2015. Tese, Universidade Luterana do Brasil, 2015.

SILVA, Tatiane Santos; LANDIM, Myrna Friederichs; SOUZA, Verônica dos Reis Mariano. A utilização de recursos didáticos no processo de ensino e aprendizagem de ciências de alunos com deficiência visual. Revista Electrónica de Enseñanza de las Ciencias (REEC), v. 13, n. 1, p. 32-47, 2014.

SORRELL, Melanie et al. Creating an online scientific art exhibit formatted for people with a visual impairment. Journal of Web Librarianship, v. 11, n. 2, p. 105-123, 2017. 
STELLA, Larissa Ferreira; MASSABNI, Vânia Galindo. Ensino de Ciências Biológicas: materiais didáticos para alunos com necessidades educativas especiais. Ciência \& Educação (Bauru), v. 25 , n. 2 , p. 353-374, 2019.

TORRES, Josiane Pereira; SANTOS, Vivian. Conhecendo a deficiência visual em seus aspectos legais, históricos e educacionais. Educação (Batatais), v. 5, n. 2, p. 33-52, 2015.

TRIEF, Ellen; LENGEL, Jim; BAECHER, Laura. A national video library for teacher preparation in visual impairments. Journal of Visual Impairment \& Blindness, v. 107, n. 1, p. 55-59, 2013.

TUlLIO, Mírian Izabel. Os Desafios da Escola Pública Paranaense na Perspectiva do Professor PDE. Paraná: Seed-Unicentro, 2015.

VAZ, José Murilo Calixto, et al. Material didático para ensino de biologia: possibilidades de inclusão. Revista brasileira de pesquisa em educação em ciências, 12.3, p. 81-104, 2012.

VIVEIROS, Edval Rodrigues. Mindware semiótico-comunicativo: campos conceituais no ensino de física para deficientes visuais utilizando uma interface cérebro-computador. Bauru: Unesp, 2013. Tese, Universidade Estadual Paulista, 2013.

VOOS, Ivani Cristina. O ensino de Ciências da Natureza para estudantes cegos e baixa visão no desenvolvimento profissional de docentes da Educação Especial: por que não? Florianópolis: UFSC, 2018. Tese, Universidade Federal de Santa Catarina, 2018.

ZHOU, Li et al. Assistive technology for students with visual impairments: Challenges and needs in teachers' preparation programs and practice. Journal of Visual Impairment \& Blindness, v. 105 , n. 4 , p. $197-210,2011$. 